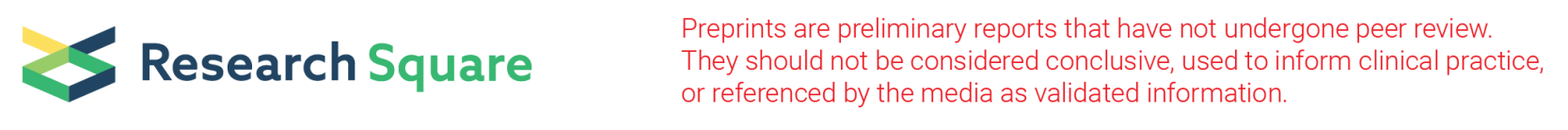

\title{
Association Between Risk of VTE and Mortality in Patients with COVID-19
}

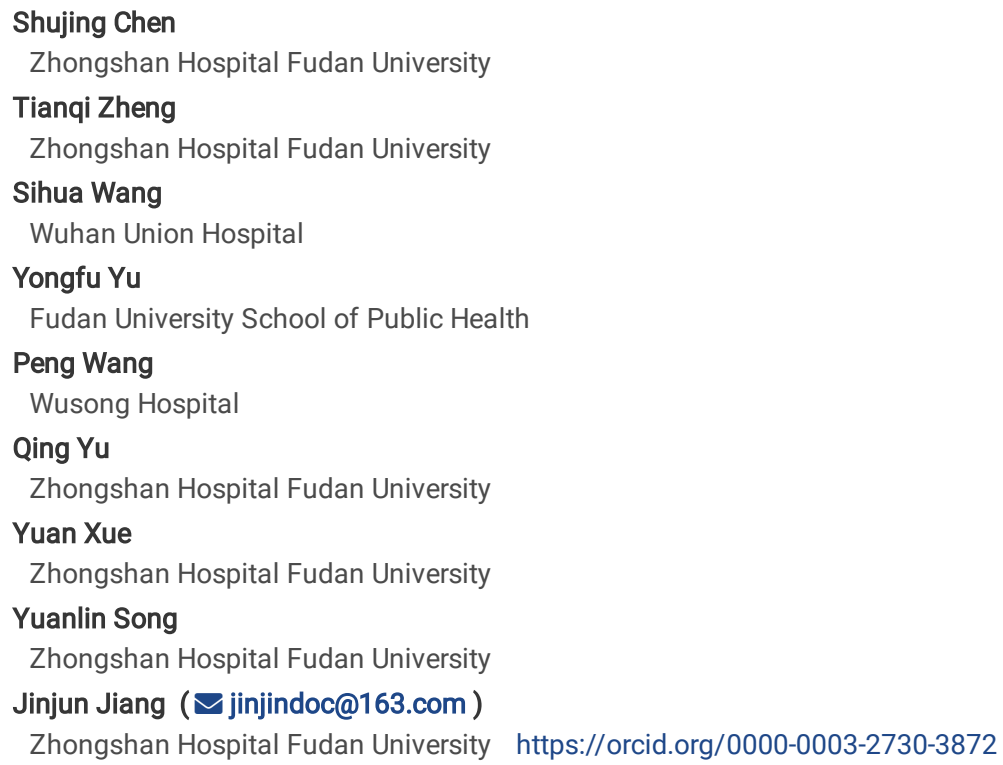




\section{Abstract}

Background: Hospitalized patients with COVID-19 appeared high risk of venous thromboembolism (VTE), which exhibited the predictor of mortality in nonCOVID-19 patients.

Objectives: We aimed to investigate the association between risk of VTE with 30-day mortality in COVID-19 patients.

Methods: In this retrospective cohort study, 1030 consecutive hospitalized patients with COVID-19 were recruited in two hospitals of Wuhan, China. We collected baseline data on demographics, SOFA parameters, and VTE risk assessment models (RAMs) including Padua Prediction Score (PPS), IMPROVE and Caprini RAM. The primary outcome of the study was 30-day mortality.

Results: Thirty-day mortality increased progressively from $2 \%$ in patients at low risk of VTE to $63 \%$ in those at high risk defined by PPS. Similar findings were also observed for risk of VTE defined by IMPROVE and Caprini score. Progressive increases in VTE risk also were associated with higher SOFA score. Our findings showed that the presence of high risk of VTE was independently associated with 30-day mortality regardless of adjusted gender, smoking status and some comorbidities with hazard ratios of $29.19,37.37,20.60$ for PPS, IMPROVE and Caprini RAM, respectively ( $P<0.001$ for all comparisons). Predictive accuracy of PPS (AUC, 0.900), IMPROVE (AUC, 0.917) or Caprini RAM (AUC, 0.861) as the risk of 30-day mortality was markedly well.

Conclusions: The presence of high risk of VTE identifies a group of patients with COVID-19 at higher risk for 30-day mortality. Furthermore, there is higher accuracy of VTE RAMs to predict 30-day mortality in these patients.

\section{Introduction}

Hospitalized patients with COVID-19 exhibit an increased risk of developing venous thromboembolism (VTE).[1] For those patients, it is proposed to apply Padua Prediction Score (PPS) or International Medical Prevention Registry (IMPROVE) risk assessment models (RAM) to detect the risk stratification of VTE, guiding thromboprophylaxis.[2] Several VTE RAMs have been conducted from large cohorts of acutely ill hospitalized medical patients and introduced to individualize VTE risk of hospitalized patients.[3]

However, the VTE RAMs were interestingly found the novel predictive ability, which demonstrated higher PPS and IMPROVE score were both associated with mortality of medical patients.[4] Septic patients with higher Padua Prediction Score (PPS) had been displayed higher mortality risk.[5] A subsequent study has indicated that not only higher PPS but also IMPROVE RAM score were associated with early mortality in infectious and other medical diseases.[6] These studies indicated that high risk of VTE, defined by higher VTE RAMs score, was associated with mortality risk in sepsis or other medical ill patients.

A study Of 1026 COVID-19 patients shown that the mortality of patients at high risk of VTE(PPS $\geq 4$ ), was increased compared to patients at low risk of VTE (PPS < 4).[7] This study, however, had three major limitations. One is that age data were not available for all patients which is one of 11 parameters of PPS. Another is the proportion of critical patients was much lower as the mortality was only $1.4 \%$. Finally, difference between these two groups was not checked by statistical analysis. Then conclusion cann't be made that high risk of VTE was associated with the risk of mortality in COVID-19 patients.

To date, there is little evidence on the relation between risk of VTE and mortality in COVID-19 patients. Then in this study, we evaluated the association between risk of VTE with the mortality from any cause in COVID-19 patients.

\section{Methods}

\section{Setting and Study Population}

This multicenter, retrospective, cohort study analyzed 1082 patients with COVID-19 in Jinyintan Hospital $(n=837)$ and Union Hosptial, Tongji Medical College, Huazhong University of Science and Technology $(n=245)$ in Wuhan, China from January 26, 2020 to March 29, 2020 (Fig. 1). All patients met the diagnostic criteria according to the World Health Organization interim guidance.[8] The study was approved by Jinyintan Hospital Ethics Committee (KY-2020-06.01) and Union Hospital Ethics Committee (2020-0039). Written informed consent was waived by the Ethics Commission.

\section{Data Collection}

A trained team of physicians retrospectively reviewed clinical electronic medical records and laboratory findings for all the patients. We collected data on age, sex, BMI, smoking status, the dates of hospital admission and discharge or death, the length of hospital stay, chronic disease history (hypertension, coronary heart disease, diabetes, hematencephalon, cerebral infarction, malignancy, digestive system disease, respiratory system disease, thyroid disease, etc) and bleeding events. Charlson Comorbidity Index score was included, which with higher scores indicated a greater burden of illness.[9] The forms of respiratory support were collected. RAMs of VTE (PPS,[10] IMPROVE RAM,[11] and Caprini RAM[12]), and Sequential Organ Failure Assessment (SOFA score)[13] at admission were calculated retrospectively according to the medical records by a blinded reviewer (critical care fellow). Due to VTE RAMs information missing, 52 patients were excluded (Fig. 1). About 43.5\% patients received pharmacologic thromboprophylaxis (low-molecular-weight heparin, LMWH, subcutaneous injection) after admission according to their venous thromboembolism risk assessment and bleeding risk assessment.[13, 12] In this study, we did not collect the data of the incidence of VTE and bleeding events for two main reasons. Firstly, our aim was to assess the relationship between VTE RAMs and mortality. On the other hand, the incidence of VTE and bleeding events might be bias restricted by medical conditions. 


\section{Risk Assessment Model And Definitions}

The RAMs adopted in this study included PPS, IMPROVE RAM, and Caprini RAM. The risk profile for VTE of PPS is calculated by 11 risk factors. A cumulative PPS $\geq 4$ and $<4$ was defined as high risk and low risk of VTE respectively. IMPROVE RAM consists of 7 risk factors. An overall score of 4 or higher was considered to be high risk of VTE. The score of 2-3 and 0-1 was considered to moderate risk and low risk respectively. Based on the 39 weighted risk factors of the Caprini RAM, patients were classified to four risk grades: "low risk" (score 0-1), "moderate risk" (score 2), "high risk" (3-4), or "highest risk" ( $\geq 5$ ).[14] But in this study, we merged "low risk" and "moderate risk" groups of patients (score 0-2), and re-classified the risk grade as "low risk" (score 0-2), "moderate risk" (score 3-4), and "high risk" (score $\geq 5$ ) for clinical characteristics analysis. Furthermore, we paid more attention to the "highest risk" group (score $\geq 5$ ) for risk of mortality analysis based on data balancing.

\section{Outcomes}

The primary outcome of the study was 30-day mortality. The secondary outcome was the length of stay in hospital.

\section{Statistical Analysis}

Descriptive data were expressed as mean (SD) or median (IQR) for continuous variables and number (\%) for categorical variables. Comparison of continuous variables was examined by independent Student's t-test and Mann-Whitney U test. Statistical analysis of categorical variable was performed using Pearson chi-square test and Fisher's exact test as appropriate. Cox regression was used to estimate hazard ratio (HR) with $95 \%$ confidence interval (Cl) to evaluate the association between risk of VTE and mortality with adjustment for sex, age, platelet, severity, smoking status and comorbidity. Receiver operating characteristic (ROC) curve was performed to estimate the sensitivity, specificity, positive predictive value (PPV), negative predictive value (NPV), and area under ROC curve (AUC) of VTE RAMs to predict mortality. The optimal prediction threshold of VTE RAMs was defined as the cut-off point corresponding to the maximum difference between sensitivity and 1-specificity. Kaplan-Meier method was performed to estimate cumulative 30-day mortality after hospital admission. All statistical analyses were performed using SAS 9.4 and Stata 12.

\section{Results}

We retrospectively enrolled 1030 consecutively identified patients with COVID-19 in Union hospital and Jinyintan hospital of Wuhan (Fig. 1, Table 1). Upon admission to hospital, the mean SOFA score was 3 (IQR 2-5). $28.3 \%$ of patients required mechanical ventilation. $17.3 \%$ and $44.9 \%$ had hypoxemia requiring high flow nasal cannula oxygen therapy (HFNC) and conventional oxygen therapy respectively (Table 1). Overall, the median age of the patients was 47 years (IQR 44-65). A total of $44.1 \%$ were female. The in-hospital length of stay was 12 (IQR 8-16) days. All-cause 30 -day mortality was $20.7 \%$ (95\% Cl, $14.1-30.0)$. 
Table 1

Comparison of clinical characteristics of COVID-19 patients between RAMs-based grouping

\begin{tabular}{|c|c|c|c|c|c|c|c|c|c|c|c|}
\hline & $\begin{array}{l}\text { All } \\
\text { patients }\end{array}$ & $\begin{array}{l}\text { Padua } \\
\text { Prediction } \\
\text { Score }<4\end{array}$ & $\begin{array}{l}\text { Padua } \\
\text { Prediction } \\
\text { Score } \geq 4\end{array}$ & $\begin{array}{l}P \\
\text { value }\end{array}$ & $\begin{array}{l}\text { IMPROVE } \\
\text { Score 0- } \\
1\end{array}$ & $\begin{array}{l}\text { IMPROVE } \\
\text { Score 2- } \\
3\end{array}$ & $\begin{array}{l}\text { IMPROVE } \\
\text { Score } \geq 4\end{array}$ & $\begin{array}{l}P \\
\text { value }\end{array}$ & $\begin{array}{l}\text { Caprini } \\
\text { Score 0-2 }\end{array}$ & $\begin{array}{l}\text { Caprini } \\
\text { Score } \\
3-4\end{array}$ & $\begin{array}{l}\text { Caprini } \\
\text { Score } \\
\geq 5\end{array}$ \\
\hline Number, cases & 1030 & 707 & 323 & & 739 & 259 & 32 & & 152 & 496 & 382 \\
\hline $\begin{array}{l}\text { Age, years, } \\
\text { median (IQR) }\end{array}$ & $\begin{array}{l}55 \\
(44,65)\end{array}$ & $51(41,62)$ & $63(51,72)$ & $<001$ & $51(41,62)$ & $63(53,72)$ & $68(55,75)$ & $<001$ & $35(30,40)$ & $52(45,60)$ & $65(57,74$ \\
\hline Sex & & & & $<.001$ & & & & $<.001$ & & & \\
\hline Male, n (\%) & 576 & $363(51 \%)$ & $213(66 \%)$ & & $386(52 \%)$ & $164(63 \%)$ & $26(81 \%)$ & & $80(53 \%)$ & $258(52 \%)$ & $238(62 \%$ \\
\hline Female, n (\%) & 454 & $344(49 \%)$ & $110(34 \%)$ & & $353(48 \%)$ & $95(37 \%)$ & $6(19 \%)$ & & $72(47 \%)$ & $238(48 \%)$ & 144(38\% \\
\hline $\begin{array}{l}\mathrm{BMI}, \mathrm{kg} / \mathrm{m}^{2} \\
\text { median (IQR) }\end{array}$ & 1030 & $23(22,26)$ & $24(23,26)$ & 0.244 & $23(22,26)$ & $24(23,26)$ & $23(21,27)$ & 0.232 & $23(21,24)$ & $24(22,26)$ & $24(23,27$ \\
\hline $\begin{array}{l}\text { SOFA score, } \\
\text { median (IQR) }\end{array}$ & $3(2,5)$ & $2(2,3)$ & $7(5,8)$ & 0 & $3(2,3)$ & $7(5,8)$ & $6.5(5,8)$ & $<0.001$ & $2(0,3)$ & $3(2,3)$ & $6(4,8)$ \\
\hline $\begin{array}{l}\text { Required } \\
\text { respiratory } \\
\text { support, n (\%) }\end{array}$ & & $610(86 \%)$ & $322(99.7 \%)$ & $<.001$ & $645(87 \%)$ & $255(98 \%)$ & $32(100 \%)$ & $<0.001$ & $80(52 \%)$ & 472(95\%) & $80(99.5 \%$ \\
\hline None & 98 & $97(14 \%)$ & $1(0.3 \%)$ & & $94(13 \%)$ & $4(2 \%)$ & $0(0 \%)$ & & $72(48 \%)$ & $24(5 \%)$ & $2(0.5 \%)$ \\
\hline $\begin{array}{l}\text { Conventional } \\
\text { oxygen }\end{array}$ & 462 & $455(64 \%)$ & $7(2 \%)$ & & $455(62 \%)$ & $7(3 \%)$ & $0(0 \%)$ & & $68(45 \%)$ & $382(77 \%)$ & $12(3 \%)$ \\
\hline HFNC & 178 & $155(22 \%)$ & $23(7 \%)$ & & $156(21 \%)$ & $20(7 \%)$ & $2(6 \%)$ & & $12(8 \%)$ & $76(15 \%)$ & $90(24 \%)$ \\
\hline $\begin{array}{l}\text { Noninvasive } \\
\text { ventilation }\end{array}$ & 62 & $0(0 \%)$ & $62(19 \%)$ & & $34(5 \%)$ & $26(10 \%)$ & $2(6 \%)$ & & $0(0 \%)$ & $14(3 \%)$ & $48(13 \%)$ \\
\hline $\begin{array}{l}\text { Invasive } \\
\text { mechanical } \\
\text { ventilation }\end{array}$ & 230 & $0(0 \%)$ & $230(71 \%)$ & & $0(0 \%)$ & $202(78 \%)$ & $28(88 \%)$ & & $0(0 \%)$ & $0(0 \%)$ & $230(60 \%$ \\
\hline Smoking Status, $\mathrm{n}$ & & & & 0.026 & & & & 0.003 & & & \\
\hline $\begin{array}{l}\text { Ex-smoked or } \\
\text { smoking }\end{array}$ & 108 & $64(9 \%)$ & $44(14 \%)$ & & $68(9 \%)$ & $40(15 \%)$ & $0(0 \%)$ & & $9(6 \%)$ & $48(10 \%)$ & $51(13 \%)$ \\
\hline Never-smoked & 922 & 643(91\%) & $279(86 \%)$ & & 671(91\%) & $219(85 \%)$ & $32(100 \%)$ & & $143(94 \%)$ & $448(90 \%)$ & 331(87\% \\
\hline $\begin{array}{l}\text { Charlson } \\
\text { Comorbidity } \\
\text { Index, median } \\
\text { (IQR) }\end{array}$ & 1030 & $1(0,2)$ & $3(2,5)$ & $<001$ & $1(0,2)$ & $3(2,5)$ & $6(4,7)$ & $<.001$ & $0(0,0)$ & $1(0,2)$ & $3(2,5)$ \\
\hline $\begin{array}{l}\text { Complications, } \mathrm{n} \\
(\%)\end{array}$ & 692 & $408(58 \%)$ & $284(88 \%)$ & $<.001$ & $423(57 \%)$ & $237(92 \%)$ & $32(100 \%)$ & $<.001$ & $55(36 \%)$ & $307(62 \%)$ & $330(86 \%$ \\
\hline \multicolumn{12}{|l|}{$\begin{array}{l}\text { Medical history, n } \\
(\%)\end{array}$} \\
\hline Hypertension & 322 & $187(26 \%)$ & $135(42 \%)$ & $<0.001$ & $196(27 \%)$ & $117(45 \%)$ & $9(28 \%)$ & $<001$ & $16(11 \%)$ & $139(28 \%)$ & 167(44\% \\
\hline Diabetes mellitus & 159 & $110(16 \%)$ & $148(46 \%)$ & $<0.001$ & $120(16 \%)$ & $114(44 \%)$ & $24(75 \%)$ & $<001$ & $14(9 \%)$ & $81(16 \%)$ & 163(43\% \\
\hline Hematencephalon & 4 & $1(0.1 \%)$ & $3(1 \%)$ & 0.059 & $1(0.1 \%)$ & $3(1 \%)$ & $0(0 \%)$ & 0.070 & $0(0 \%)$ & $1(0.2 \%)$ & $3(1 \%)$ \\
\hline $\begin{array}{l}\text { Cerebral } \\
\text { infarction }\end{array}$ & 84 & $39(6 \%)$ & $45(14 \%)$ & $<.001$ & $38(5 \%)$ & $44(17 \%)$ & $2(6 \%)$ & $<.001$ & $152(100 \%)$ & $30(6 \%)$ & $54(14 \%)$ \\
\hline Malignancy & 62 & $4(1 \%)$ & $58(18 \%)$ & $<.001$ & $1(0.1 \%)$ & $29(11 \%)$ & $32(100 \%)$ & $<.001$ & $1(1 \%)$ & $7(1 \%)$ & $54(14 \%)$ \\
\hline Thyroid diseases & 59 & $40(6 \%)$ & $19(6 \%)$ & 0.886 & $40(5 \%)$ & $18(7 \%)$ & $1(3 \%)$ & 0.534 & $16(11 \%)$ & $23(5 \%)$ & $20(5 \%)$ \\
\hline $\begin{array}{l}\text { Coronary heart } \\
\text { disease }\end{array}$ & 101 & $50(7 \%)$ & $51(16 \%)$ & $<.001$ & $51(7 \%)$ & $44(17 \%)$ & $6(19 \%)$ & $<0.001$ & $1(1 \%)$ & $35(7 \%)$ & $65(17 \%)$ \\
\hline $\begin{array}{l}\text { Digestive system } \\
\text { disease }\end{array}$ & 103 & $63(9 \%)$ & $40(12 \%)$ & 0.085 & $65(9 \%)$ & $31(12 \%)$ & $7(22 \%)$ & 0.026 & $6(4 \%)$ & $51(10 \%)$ & $46(12 \%)$ \\
\hline Hepatitis & 48 & $23(3 \%)$ & $25(8 \%)$ & 0.002 & $24(3 \%)$ & $17(7 \%)$ & $7(22 \%)$ & $<.001$ & $2(1 \%)$ & $19(4 \%)$ & $27(7 \%)$ \\
\hline Fatty liver & 6 & $5(1 \%)$ & $1(0.3 \%)$ & 0.437 & $5(1 \%)$ & $1(0.4 \%)$ & $0(0 \%)$ & 0.789 & $3(2 \%)$ & $2(0.4 \%)$ & $1(0.3 \%)$ \\
\hline
\end{tabular}




\begin{tabular}{|c|c|c|c|c|c|c|c|c|c|c|c|}
\hline & $\begin{array}{l}\text { All } \\
\text { patients }\end{array}$ & $\begin{array}{l}\text { Padua } \\
\text { Prediction } \\
\text { Score }<4\end{array}$ & $\begin{array}{l}\text { Padua } \\
\text { Prediction } \\
\text { Score } \geq 4\end{array}$ & $\begin{array}{l}P \\
\text { value }\end{array}$ & $\begin{array}{l}\text { IMPROVE } \\
\text { Score 0- } \\
1\end{array}$ & $\begin{array}{l}\text { IMPROVE } \\
\text { Score 2- } \\
3\end{array}$ & $\begin{array}{l}\text { IMPROVE } \\
\text { Score } \geq 4\end{array}$ & $\begin{array}{l}P \\
\text { value }\end{array}$ & $\begin{array}{l}\text { Caprini } \\
\text { Score 0-2 }\end{array}$ & $\begin{array}{l}\text { Caprini } \\
\text { Score } \\
3-4\end{array}$ & $\begin{array}{l}\text { Caprini } \\
\text { Score } \\
\geq 5\end{array}$ \\
\hline $\begin{array}{l}\text { Respiratory } \\
\text { system disease }\end{array}$ & 71 & $46(7 \%)$ & $25(8 \%)$ & 0.468 & $47(6 \%)$ & $23(9 \%)$ & $1(3 \%)$ & 0.269 & $5(3 \%)$ & $34(7 \%)$ & $32(8 \%)$ \\
\hline COPD & 31 & $14(2 \%)$ & $17(5 \%)$ & 0.004 & $15(2 \%)$ & $16(6 \%)$ & $0(0 \%)$ & 0.002 & $0(0 \%)$ & $11(2 \%)$ & $20(5 \%)$ \\
\hline Bronchiectasia & 16 & $11(2 \%)$ & $5(2 \%)$ & 0.992 & $11(1 \%)$ & $5(2 \%)$ & $0(0 \%)$ & 0.682 & $2(1 \%)$ & $0(2 \%)$ & $5(1 \%)$ \\
\hline $\begin{array}{l}\text { In-hospital length } \\
\text { of stay, days, } \\
\text { median (IQR) }\end{array}$ & $12(8,16)$ & $12(8,16)$ & $11(7,17)$ & 0.361 & $12(8,16)$ & $11(7,17)$ & $10(8,17.5)$ & 0.335 & $11(7,15.5)$ & $12(9,16)$ & $11(7,17)$ \\
\hline Mortality, n (\%) & 213 & $11(2 \%)$ & $202(63 \%)$ & $\hat{0}_{0.001}$ & $12(2 \%)$ & $170(66 \%)$ & $31(97 \%)$ & $\hat{0}_{0.001}^{<}$ & $0(0 \%)$ & $12(2 \%)$ & $201(53 \%$ \\
\hline
\end{tabular}

We detect statistically significant differences in baseline characteristics according to the risk of VTE defined by RAMs (Table 1). According to PPS, patients were stratified as high and low risk of VTE subgroup. Patients at high risk of VTE were older, more male, more ex-smoked or smoking, more mechanical ventilation, higher mortality, whereas those with low risk of VTE were more likely to receive conventional oxygen or (HFNC). The severity of illness as assessed by incremental SOFA scores and mechanical ventilation, correlated with increasing risk of VTE. We failed to detect a difference in BMI and in-hospital length of stay. In high risk of VTE subgroup rates of all comorbidities except hematencephalon, thyroid diseases and digestive system disease appeared higher than in low risk subgroup. For example, patients at high risk of VTE were significantly more likely to have an underlying malignancy, hypertension, coronary heart disease, cerebral infarction, diabetes mellitus (DM) and chronic obstructive pulmonary disease (COPD) compared with patients at low risk of VTE.

According to IMPROVE or Caprini RAM, patients were stratified as high, moderate and low VTE risk subgroup. The age, the rates of some comorbidities, such as diabetes, coronary heart disease and hepatitis increased with the severity of VTE risk. Furthermore, the 30-day mortality varied by VTE risk level. We found similarly statistically significant differences in baseline characteristics between high and low risk subgroup according IMPROVE or Caprini RAM, as categorized by PPS.

Kaplan-Meier curves confirmed the greater mortality among patients at high risk of VTE compared with those at low risk of VTE in all subgroups stratified by these three VTE RAMs (Fig. 2). Multivariable analyses are shown in Table 2. The presence or absence of high risk of VTE (PPS or IMPROVE RAM score $\geq 4$, Caprini RAM score $\geq 5$ ), as well as the severity of VTE risk, was independently associated with 30-day mortality regardless adjusted gender, smoking status, some comorbidities. We found higher hazard ratio (HRs) in the presence of high risk of VTE, such as 29.19 ( $95 \% \mathrm{Cl}, 15.76$ to 54.05$), 37.37$ (95\% $\mathrm{Cl}, 18.43$ to 75.78), 20.60 (95\% Cl, 11.41 to 37.19) for PPS, IMPROVE or Caprini RAM respectively. We computed the ROC curves to assess the accuracy of the VTE RAMs in predicting in-hospital mortality. The AUC were 0.90 (95\% Cl 0.88 to 0.92 ), 0.92 ( $95 \% \mathrm{Cl} 0.90$ to 0.936 ), and 0.86 (95\% $\mathrm{Cl} 0.84$ to 0.88 ) for Padua, IMPROVE, and Caprini RAM respectively (Fig. 3). At the cutoff point for high risk (PPS $\geq 4$ ), the model had a negative predictive value (NPV) of $98.4 \%$ ( $95 \% \mathrm{Cl}, 97.2$ to 99.2\%), a positive predictive value (PPV) of $62.5 \%$ (95\% Cl, 57.0 to $67.8 \%$ ), a sensitivity of $94.8 \%(95 \% \mathrm{Cl}, 90.9$ to $97.4 \%)$ and a specificity of $85.2 \%$ (95\% $\mathrm{Cl}$, 82.6 to $87.6 \%$ ) for 30-day mortality (Table 3). Similar findings were also demonstrated according for IMPROVE and Caprini RAM.

Table 2

Hazard ratio of mortality according to VTE RAMs

\begin{tabular}{|c|c|c|c|}
\hline Risk factors & Hazard ratio & $95 \% \mathrm{Cl}$ & $P$ value \\
\hline \multicolumn{4}{|c|}{ Padua Prediction Score* } \\
\hline$<4$ & 1 (ref) & & \\
\hline$\geq 4$ & 29.19 & $15.76,54.05$ & $<0.001$ \\
\hline \multicolumn{4}{|c|}{ IMPROVE Score ${ }^{\#}$} \\
\hline $0-1$ & 1 (ref) & & \\
\hline $2-3$ & 30.79 & $17.12,56.02$ & $<0.001$ \\
\hline$\geq 4$ & 37.37 & $18.43,75.78$ & $<0.001$ \\
\hline \multicolumn{4}{|c|}{ Caprini Score $\varnothing^{\emptyset}$} \\
\hline $0-4$ & 1 (ref) & & \\
\hline$\geq 5$ & 20.60 & $11.41,37.19$ & $<0.001$ \\
\hline \multicolumn{4}{|c|}{ *Adjusted gender, smoking status, comorbidities (hypertension, diabetes, hepatitis) } \\
\hline \multicolumn{4}{|c|}{ \#Adjusted gender, smoking status, comorbidities (hypertension, diabetes, hepatitis) } \\
\hline \multicolumn{4}{|c|}{${ }^{\emptyset}$ Adjusted gender, smoking status, comorbidities (hypertension, diabetes). } \\
\hline
\end{tabular}


Table 3

Diagnostic accuracy of VTE RAMs for prediction of 30-day mortality

\begin{tabular}{|llll|}
\hline & Padua Prediction Score $\geq 4$ & IMPROVE Score $\geq 2$ & Caprini Score $\geq 5$ \\
\hline AUC $(95 \% \mathrm{Cl})$ & $0.900(0.881,0.919)$ & $0.917(0.898,0.936)$ & $0.861(0.840,0.882)$ \\
\hline Sensitivity $(95 \% \mathrm{Cl})$ & $94.8 \%(90.9 \%, 97.4 \%)$ & $94.4 \%(90.4 \%, 97.1 \%)$ & $94.4 \%(90.4 \%, 97.1 \%)$ \\
\hline Specificity $(95 \% \mathrm{Cl})$ & $85.2 \%(82.6 \%, 87.6 \%)$ & $89.0 \%(86.6 \%, 91.0 \%)$ & $77.8 \%(74.8 \%, 80.6 \%)$ \\
\hline Positive predictive value $(95 \% \mathrm{Cl})$ & $62.5 \%(57.0 \%, 67.8 \%)$ & $69.1 \%(63.4 \%, 74.3 \%)$ & $52.6 \%(47.5 \%, 57.7 \%)$ \\
\hline Negative predictive value $(95 \% \mathrm{Cl})$ & $98.4 \%(97.2 \%, 99.2 \%)$ & $98.4 \%(97.2 \%, 99.2 \%)$ & $98.1 \%(96.8 \%, 99.0 \%)$ \\
\hline Abbreviation: AUC, area under the ROC curve & & \\
\hline
\end{tabular}

\section{Discussion}

To our knowledge, this is the first retrospective, multicenter study to investigate the association between the risk of VTE and the risk of 30-day mortality in patients admitted to hospital with COVID-19. Our findings identify that the presence of high risk of VTE as defined by elevated score of Padua, IMPROVE or Caprini RAM correlates with a group of patients with COVID-19 at elevated risk of mortality. In addition, there is an increasing risk of mortality as the scores of VTE RAM increase, especially from low risk of VTE to moderate and high risk of VTE. Incremental increases in VTE risk also were associated with higher SOFA score. Our findings also highlight that the presence of high risk for VTE independently correlated with 30-day mortality after controlling for patient characteristics and comorbidities. Finally, predictive accuracy of Padua, IMPROVE or Caprini RAM as hospitalized mortality predictors here reported is, unexpectedly, strong.

For treatment of COVID-19 inpatients, our results have several possible implications. Firstly, all hospitalized patients with COVID-19 should be accessed risk of VTE by these risk assessment models for decision of thromboprophylaxis. Although some guidelines recommended that all hospitalized patients should be received pharmacologic prophylaxis,[1, 15] we found there were only $31.3 \%$ inpatients at high risk of VTE, similarly to the other study.[7] This could avoid overusing anticoagulants, which may increase the risk of bleeding.

Possibly more crucial are the implications of our findings for the conduct and explanation of studies for new VTE management in COVID-19 and other medically ill patients. For example, there is controversial on the efficacy of pharmacologic prophylaxis in mortality of COVID-19 patients. A study from China indicated anticoagulant therapy did not decrease the mortality of unselected patients with COVID-19.[16] Another report from New York with 2,773 patients similarly found that systemic anticoagulation did not change the mortality of whole patients with COVID-19.[17] Subgroup analysis indicated that the mortality benefit was limited to patients with severe illness or requiring mechanical ventilation.[16, 17] The study from the UK failed to show any mortality benefit in ICU patients received anticoagulants.[18] In these three studies VTE RAMs were not used to stratify the risk of VTE and mortality of whole population was failed to improve, as patients at low VTE risk could not benefit from pharmacologic thromboprophylaxis compared with patients at high risk. As to now, two large RCTs failed to identify that the use of heparin or low-molecular-weight heparin reduced the mortality of patients with sepsis or acute ill medical patients.[19, 20] In the two studies, the risk of VTE was not assessed yet. According to our data, patients with low risk of VTE appeared extremely low mortality. A potential implication for pharmacologic thromboprophylaxis as a COVID-19 or sepsis therapeutic may be studied with patients at high risk of VTE. We detect an interesting feature that these three VTE RAMs justly suggested for VTE prophylaxis in hospitalized patient can be at the same time the potential tools for the prediction of mortality in patients with COVID-19. The higher PPS was significantly correlated with risk of mortality in patients with sepsis and acute medical illness, besides reflecting risk of VTE.[5, 4] However, in similar patients with sepsis and acute medical illness, a survival benefit with anticoagulation was failed to identify. $[19,20]$ These results seemed to be counterintuitive, as the truth that anticoagulant has been shown to decrease the risk of VTE, by nearly half in hospitalized patients with acutely medical illness. Multifarious comorbidities and various other potential factors of fatality in medical patients could make fatal pulmonary embolism a less crucial determinant of mortality in this population than in surgical patients, then decreasing the ability of pharmacologic thromboprophylaxis to improve the overall survival. The parameters of PPS and other VTE RAMs, included age, immobility, comorbidities, $\mathrm{BMI}$, and so on, may reflect a more general comorbidity and disease severity index, which probably affect survival. Furthermore, they function as a comorbid index rather than a specific VTE predictor, and thus are associated with mortality rather than with risk of VTE.

The strengths of our study include its multicenter design, large and diverse sample, comprehensive data collection, as well as the feature that our enrolled proportions of high risk of VTE is relatively similar to proportions in other report,[7] which could enhance the generalizability of our findings. Moreover, we have adjusted for numerous possible confounding variables including patient characteristics and comorbidities, smoking status. Finally, we calculate the predictive accuracy of VTE RAM as mortality predictors to lend additional strength to our analysis.

There are several important limitations in this study. First, as the VTE prevention in hospitalized patients with COVID-19 was not the primary objective of our study and major patients at high risk of VTE received pharmacologic thromboprophylaxis, we did not screen for asymptomatic VTE. Second, these data are from two hospitals and may not be representative of other population in different regions and countries. There is no study provided data to detect the presence of high VTE risk in large population with COVID-19. Thereof, larger samples of COVID-19 are required to assess the true incidence of high risk of VTE in the population setting. Third, we use SOFA score to reflect the disease severity instead of APACHEX (acute physiology and chronic health evaluation scoring system), as detailed information was lacking in some modest patients. Finally, the causes of death in COVID-19 patients were judged just according to clinical characteristics, not by autopsies which were performed rarely in these two hospitals.

\section{Conclusion}


In conclusion, COVID-19 patients at high risk of VTE, as defined by PPS, IMPROVE or Caprini RAMs, appear to have a greater risk of death compared with those with low risk of VTE. We also found the good accuracy of VTE RAMs as 30-day mortality predictors. Future researches are required to verify our findings in larger populations. More importantly, future studies of COVID-19 related to the prophylaxis and mortality of VTE should take into account the risk stratification of VTE by RAMs, when formulating potential study designs.

\section{Declarations}

\section{AUTHOR CONTRIBUTIONS}

SC and JJ designed the study, SW, JJ and PW collected the data, TZ and YY analyzed the data, SC and JJ prepared drafted the paper. YS, QY, YX, SC and JJ revised the paper. All authors discussed the results and contributed to the final manuscript.

\section{CONFLICTS OF INTEREST}

The authors have no conflict of interest to disclose.

\section{ACKNOWLEDGMENTS}

This study is funded by the National Nature Science Foundation of China (81870062 to Jinjun Jiang, 81900038 to Shujing Chen).

\section{References}

1. Moores LK, Tritschler T, Brosnahan S, Carrier M, Collen JF, Doerschug K, Holley AB, Jimenez D, Le Gal G, Rali P, Wells P. Prevention, Diagnosis, and Treatment of VTE in Patients With Coronavirus Disease 2019: CHEST Guideline and Expert Panel Report. Chest. 2020;158(3):1143-63. https://doi.org/10.1016/j.chest.2020.05.559.

2. Zhai Z, Li C, Chen Y, Gerotziafas G, Zhang Z, Wan J, Liu P, Elalamy I, Wang C, Prevention Treatment of Vte Associated with Covid-19 Infection Consensus Statement Group PEPVDGotCTSPEPVDWCo. Prevention and Treatment of Venous Thromboembolism Associated with Coronavirus Disease 2019 Infection: A Consensus Statement before Guidelines. Thromb Haemost. 2020;120(6):937-48. doi:10.1055/s-0040-1710019.

3. Kahn SR, Lim W, Dunn AS, Cushman M, Dentali F, Akl EA, Cook DJ, Balekian AA, Klein RC, Le H, Schulman S, Murad MH. Prevention of VTE in nonsurgical patients: Antithrombotic Therapy and Prevention of Thrombosis, 9th ed.: American College of Chest Physicians Evidence-Based Clinical Practice Guidelines. Chest 2012 Feb;141(2 Suppl):e195S-226S. doi:10.1378/chest.11-2296. PMID: 22315261; PMCID: PMC3278052.

4. Arpaia GG, Caleffi A, Marano G, Laregina M, Erba G, Orlandini F, Cimminiello C, Boracchi P. Padua prediction score and IMPROVE score do predict inhospital mortality in Internal Medicine patients. Intern Emerg Med. 2020;15(6):997-1003. https://doi.org/10.1007/s11739-019-02264-4.

5. Vardi M, Ghanem-Zoubi NO, Zidan R, Yurin V, Bitterman H. Venous thromboembolism and the utility of the Padua Prediction Score in patients with sepsis admitted to internal medicine departments. J Thromb Haemost. 2013;11(3):467-73. doi:10.1111/jth.12108.

6. La Regina M, Orlandini F, Marchini F, Marinaro A, Bonacci R, Bonanni P, Corsini F, Ceraudo AM, Pacetti E, Scuotri L, Costabile D, Dentali F. Combined assessment of thrombotic and haemorrhagic risk in acute medical patients. Thromb Haemost. 2016;115(2):392-8. doi:10.1160/TH14-12-1050.

7. Wang T, Chen RC, Liu CL, Liang WH, Guan WJ, Tang RD, Tang CL, Zhang NF, Zhong NS, Li SY. Attention should be paid to venous thromboembolism prophylaxis in the management of COVID-19. Lancet Haematol. 2020;7(5):E362-3. doi:10.1016/S2352-3026(20)30109-5.

8. World Health Organization. Clinical management of severe acute respiratory infection when novel coronavirus (nCoV) infection is suspected. Jan 11. 2020. https://www.who.int/publications-detail/clinical-management-of- severe-acute-respiratory-infection-when-novel-coronavirus-(ncov)-infection-issuspected (accessed Feb 8, 2020).

9. de Groot V, Beckerman H, Lankhorst GJ, Bouter LM. How to measure comorbidity. a critical review of available methods. J Clin Epidemiol. 2003;56(3):221-9. doi:10.1016/s0895-4356(02)00585-1.

10. Barbar S, Noventa F, Rossetto V, Ferrari A, Brandolin B, Perlati M, De Bon E, Tormene D, Pagnan A, Prandoni P. A risk assessment model for the identification of hospitalized medical patients at risk for venous thromboembolism: the Padua Prediction Score. J Thromb Haemost. 2010;8(11):2450-7. doi:10.1111/j.1538-7836.2010.04044.x.

11. Spyropoulos AC, Anderson FA Jr, FitzGerald G, Decousus H, Pini M, Chong BH, Zotz RB, Bergmann JF, Tapson V, Froehlich JB, Monreal M, Merli GJ, Pavanello R, Turpie AGG, Nakamura M, Piovella F, Kakkar AK, Spencer FA, Investigators I. Predictive and associative models to identify hospitalized medical patients at risk for VTE. Chest. 2011;140(3):706-14. doi:10.1378/chest.10-1944.

12. Schunemann HJ, Cushman M, Burnett AE, Kahn SR, Beyer-Westendorf J, Spencer FA, Rezende SM, Zakai NA, Bauer KA, Dentali F, Lansing J, Balduzzi S, Darzi A, Morgano GP, Neumann I, Nieuwlaat R, Yepes-Nunez JJ, Zhang Y, Wiercioch W. American Society of Hematology 2018 guidelines for management of venous thromboembolism: prophylaxis for hospitalized and nonhospitalized medical patients. Blood Adv. 2018;2(22):3198-225. doi:10.1182/bloodadvances.2018022954.

13. Raith EP, Udy AA, Bailey M, McGloughlin S, Maclsaac C, Bellomo R, Pilcher DV, Australian, New Zealand Intensive Care Society Centre for O, Resource E. Prognostic Accuracy of the SOFA Score, SIRS Criteria, and qSOFA Score for In-Hospital Mortality Among Adults With Suspected Infection Admitted to the Intensive Care Unit. JAMA. 2017;317(3):290-300. doi:10.1001/jama.2016.20328.

14. Caprini JA. Thrombosis risk assessment as a guide to quality patient care. Dm-Dis Mon. 2005;51(2-3):70-8. doi:10.1016/j.disamonth.2005.02.003.

15. Spyropoulos AC, Levy JH, Ageno W, Connors JM, Hunt BJ, Iba T, Levi M, Samama CM, Thachil J, Giannis D, Douketis JD, Subcommittee on Perioperative CCTHotSSCotISoTH. Scientific and Standardization Committee Communication: Clinical Guidance on the Diagnosis, Prevention and Treatment of Venous

Page 7/11 
Thromboembolism in Hospitalized Patients with COVID-19. J Thromb Haemost. 2020. doi:10.1111/jth.14929.

16. Tang N, Bai H, Chen X, Gong JL, Li DJ, Sun ZY. Anticoagulant treatment is associated with decreased mortality in severe coronavirus disease 2019 patients with coagulopathy. J Thromb Haemost. 2020;18(5):1094-9. doi:10.1111/jth.14817.

17. Paranjpe I, Fuster V, Lala A, Russak AJ, Glicksberg BS, Levin MA, Charney AW, Narula J, Fayad ZA, Bagiella E, Zhao S, Nadkarni GN. Association of Treatment Dose Anticoagulation With In-Hospital Survival Among Hospitalized Patients With COVID-19. J Am Coll Cardiol. 2020;76(1):122-4. doi:10.1016/j.jacc.2020.05.001.

18. Sivaloganathan H, Ladikou EE, Chevassut T. COVID-19 mortality in patients on anticoagulants and antiplatelet agents. Brit J Haematol. 2020. doi:10.1111/bjh.16968.

19. Gardlund B. Randomised, controlled trial of low-dose heparin for prevention of fatal pulmonary embolism in patients with infectious diseases. Lancet. 1996;347(9012):1357-61. doi:10.1016/s0140-6736(96)91009-0.

20. Kakkar AK, Cimminiello C, Goldhaber SZ, Parakh R, Wang C, Bergmann JF, Investigators L. Low-Molecular-Weight Heparin and Mortality in Acutely III Medical Patients. New Engl J Med. 2011;365(26):2463-72. doi:10.1056/NEJMoa1111288.

\section{Figures}

1082 in-hospital patients with COVID-19 from January 26, 2020 to March 29, 2020

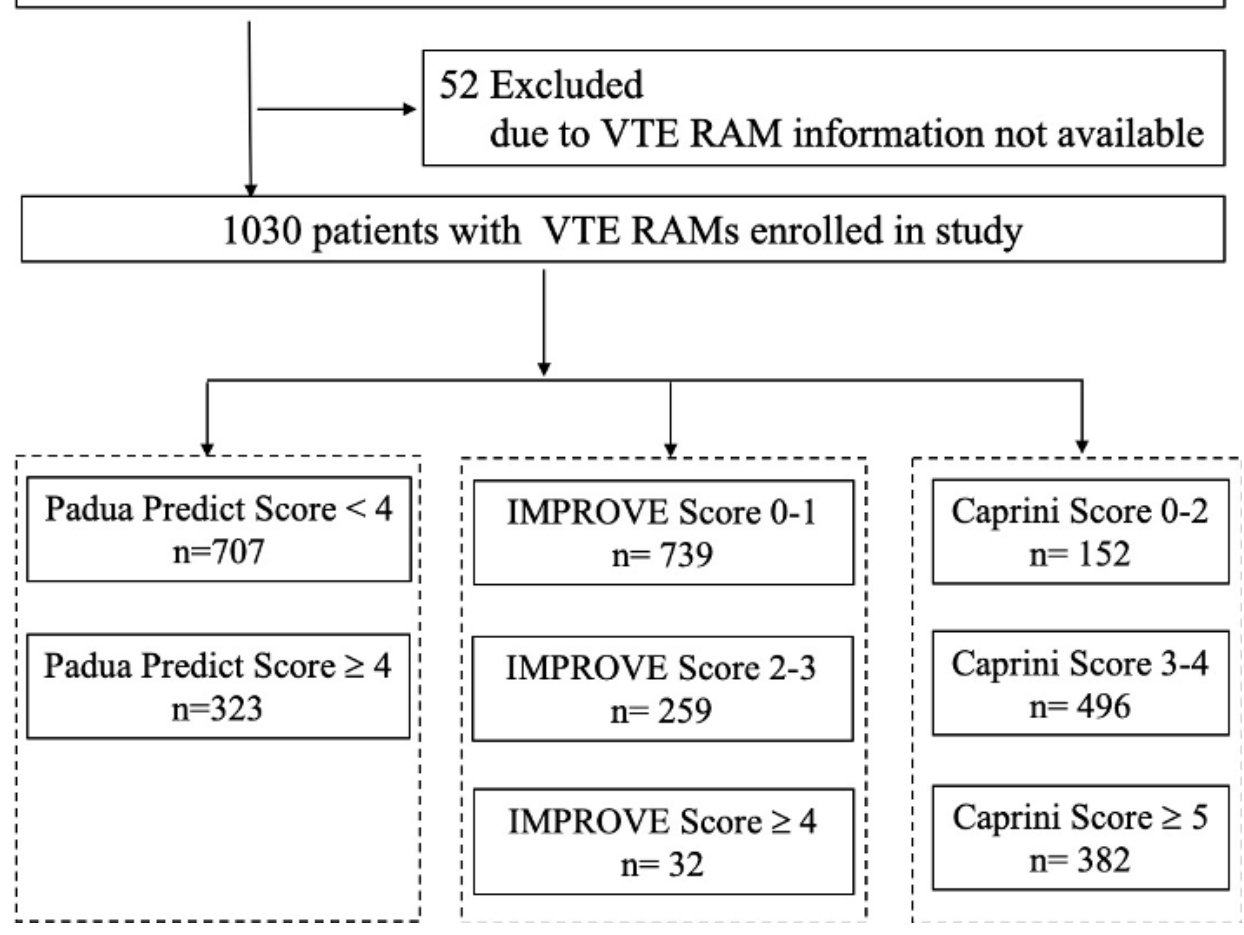

Figure 1

Flowchart of the study population. 


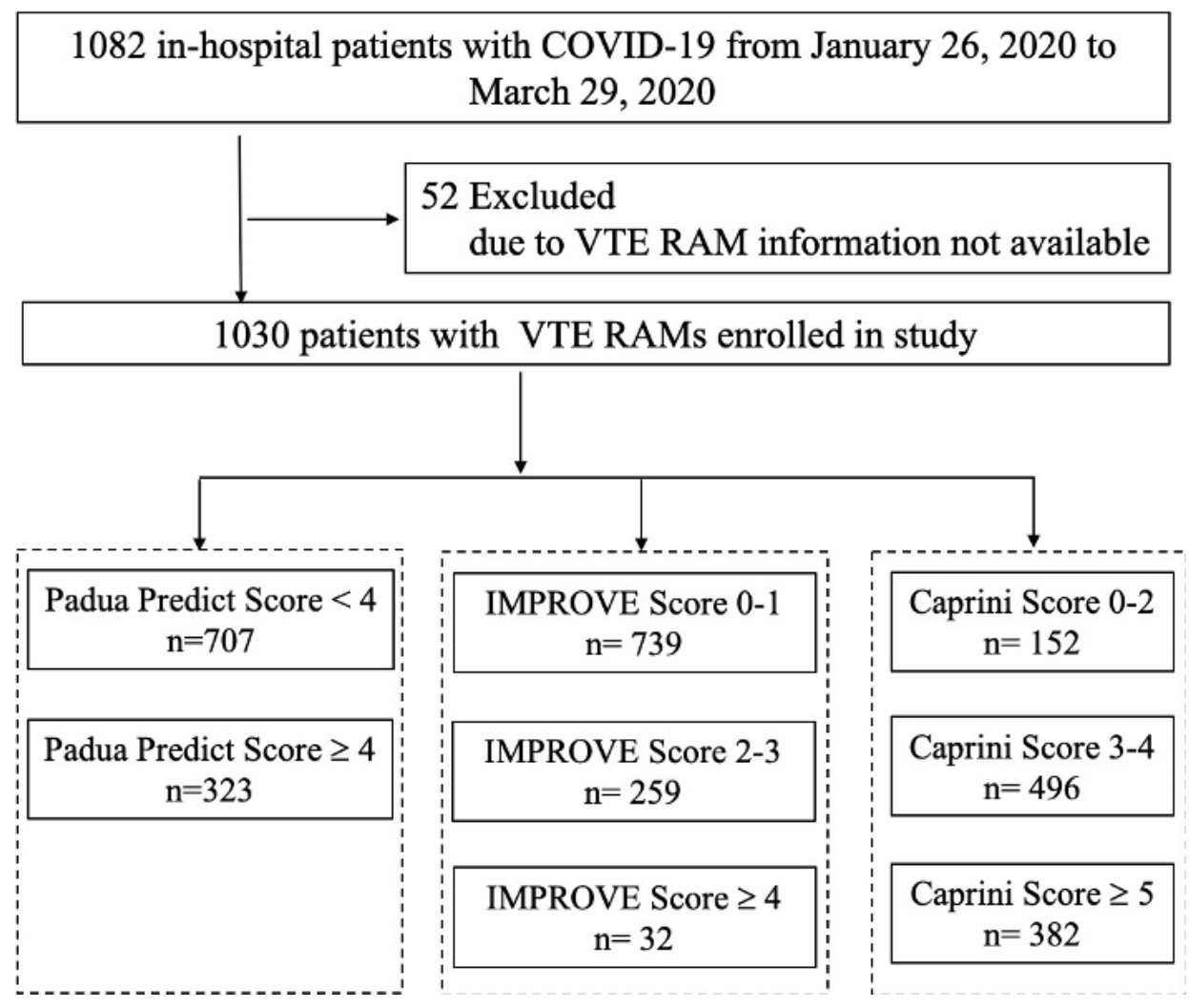

Figure 1

Flowchart of the study population.
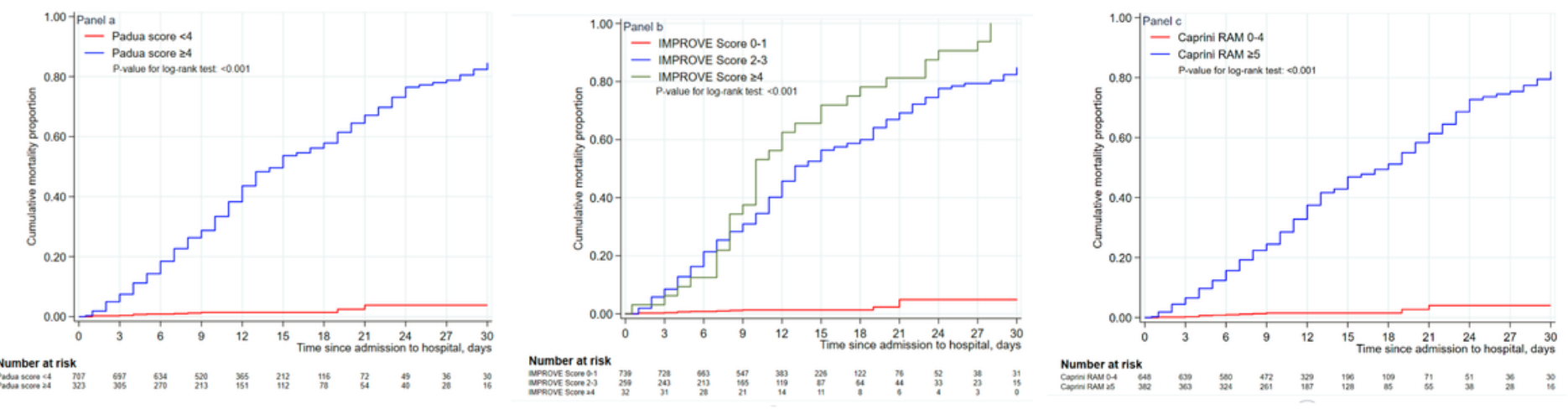

Figure 2

Kaplan-Meier curves for cumulative 30-day mortality according for different VTE risk. (A). Comparison of cumulative mortality rates between PPS < 4 and $\geq 4$ subgroup, $p<0.001$. (B). Comparison of cumulative mortality rates between IMPROVE Score $0-1,2-3$, and $\geq 4$ subgroup, $p<0.001$. (C). Comparison of cumulative mortality rates between Caprini Score between 0-4 and $\geq 5$ subgroup, $p<0.001$.
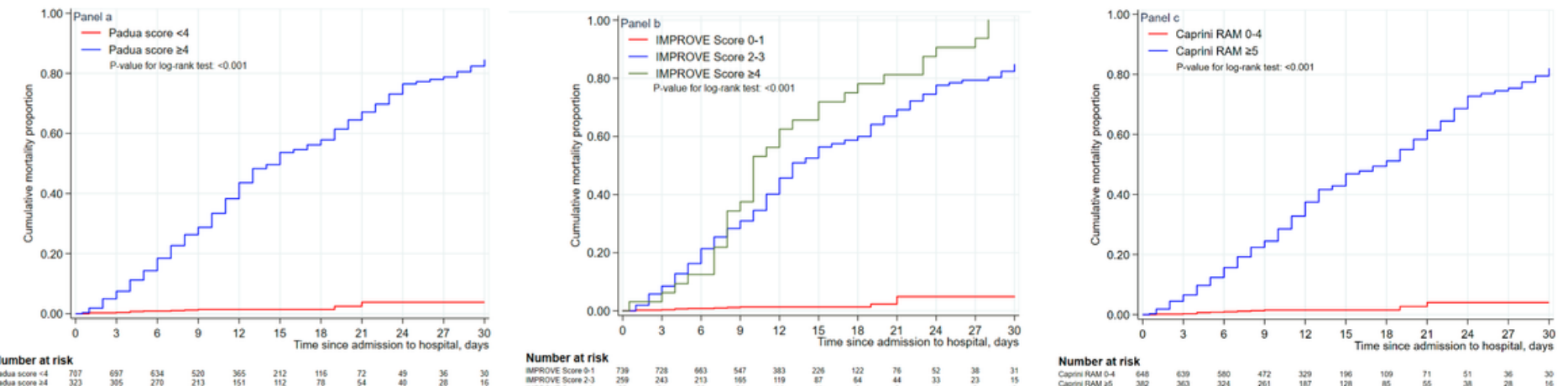

Figure 2 
Kaplan-Meier curves for cumulative 30-day mortality according for different VTE risk. (A). Comparison of cumulative mortality rates between PPS $<4$ and $\geq 4$ subgroup, $p<0.001$. (B). Comparison of cumulative mortality rates between IMPROVE Score $0-1,2-3$, and $\geq 4$ subgroup, $p<0.001$. (C). Comparison of cumulative mortality rates between Caprini Score between 0-4 and $\geq 5$ subgroup, $p<0.001$.

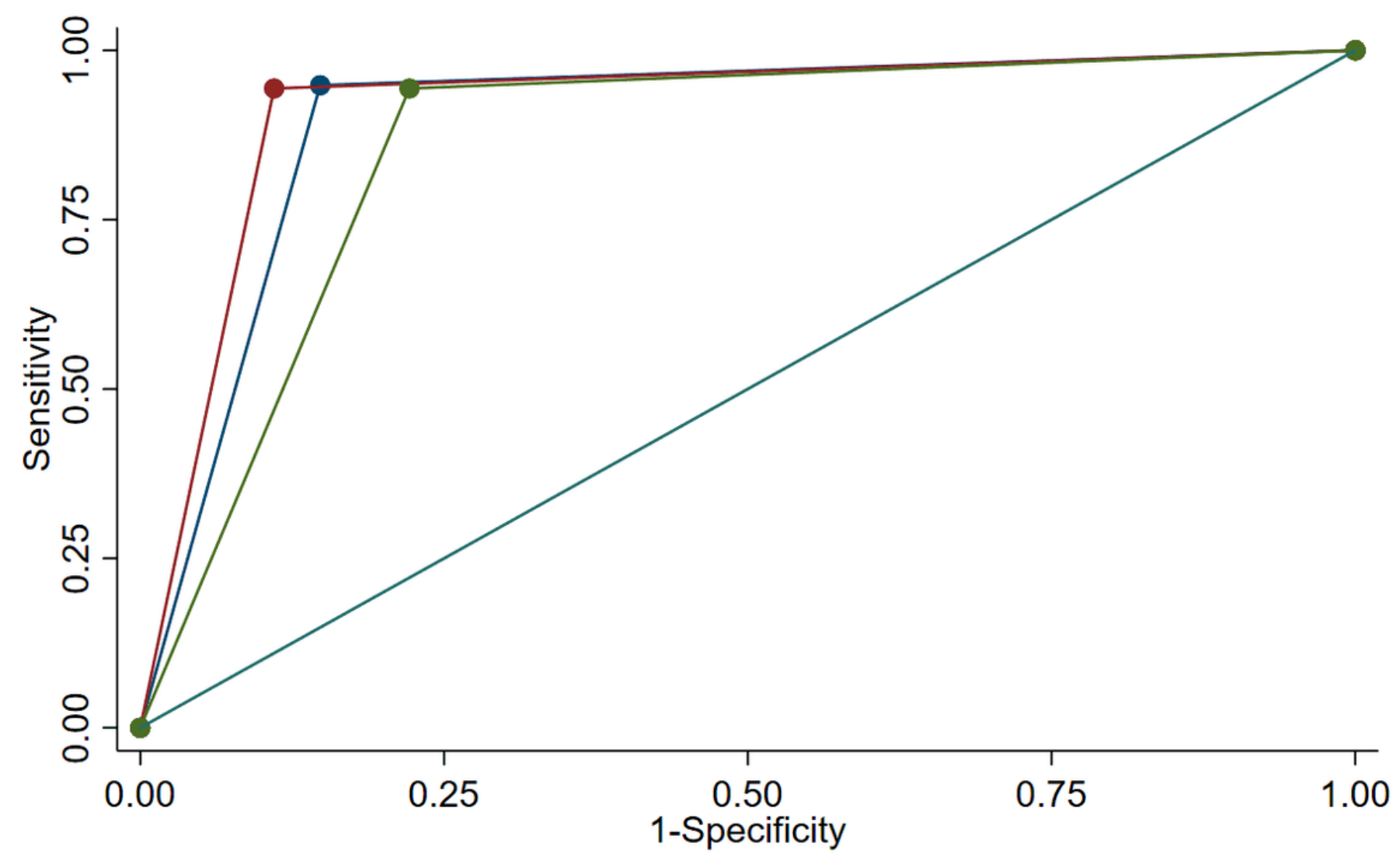

$\begin{array}{ll}\rightarrow-\text { Padua Prediction Score ROC area: } 0.90 & - \text { IMPROVE Score ROC area: } 0.92 \\ \rightarrow-\text { Caprini Score ROC area: } 0.86 & - \text { Reference }\end{array}$

Figure 3

Receiver operating characteristic (ROC) curve of the VTE RAMs (Padua Prediction Score, IMPROVE Score, and Caprini Score) for mortality prediction. 


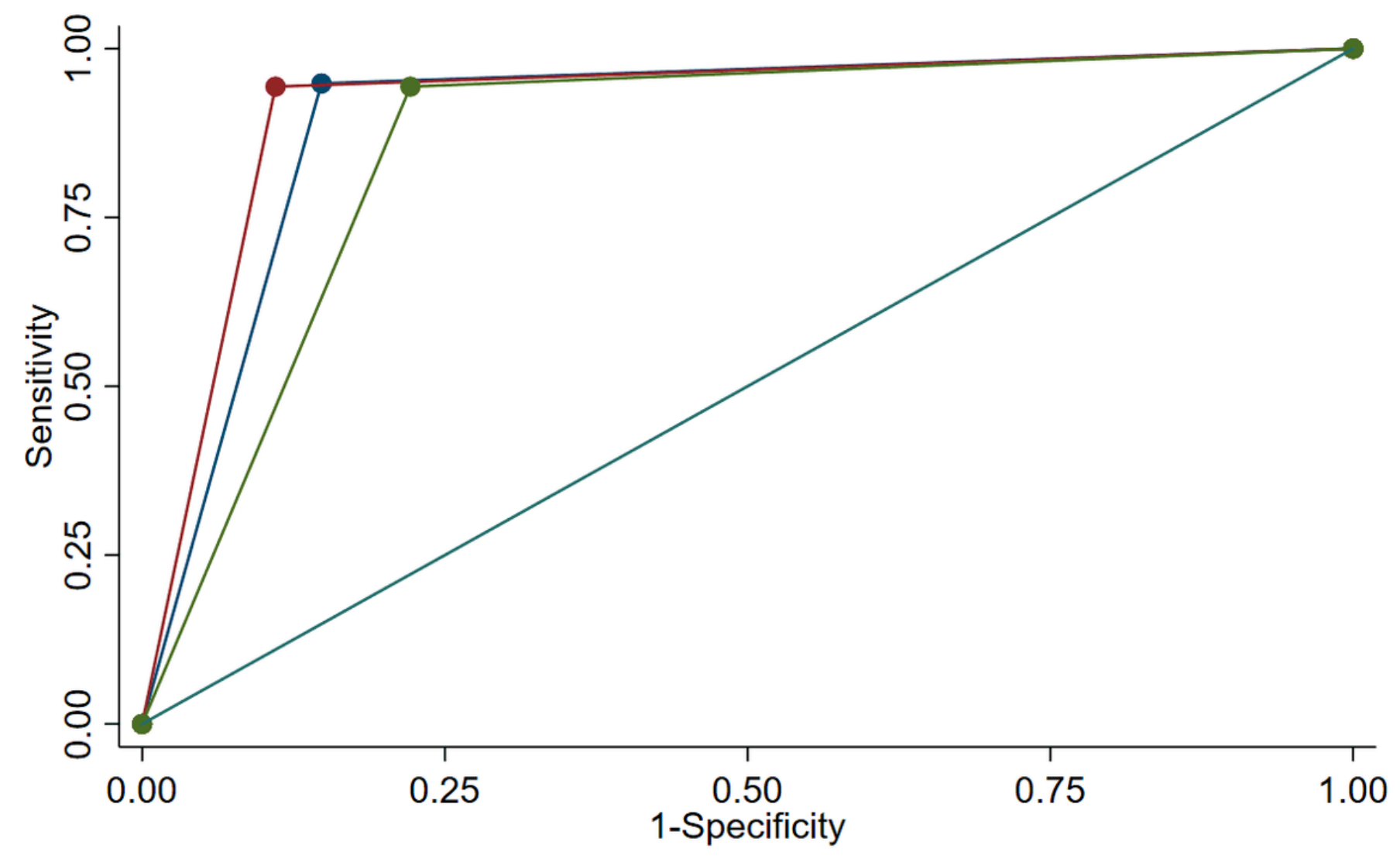

$\begin{array}{ll}\rightarrow-\text { Padua Prediction Score ROC area: } 0.90 & -- \text { IMPROVE Score ROC area: } 0.92 \\ \rightarrow-\text { Caprini Score ROC area: } 0.86 & - \text { Reference }\end{array}$

Figure 3

Receiver operating characteristic (ROC) curve of the VTE RAMs (Padua Prediction Score, IMPROVE Score, and Caprini Score) for mortality prediction. 